\title{
Retraction Note to: Simulation of coastal beach stability and coastal running based on embedded image system
}

\section{Ziyan Li ${ }^{1}$}

Published online: 12 November 2021

(c) Saudi Society for Geosciences 2021

Retraction Note to: Arabian Journal of Geosciences (2021) 14: 1074 https://doi.org/10.1007/s12517-021-07247-4

The Editor-in-Chief and the Publisher have retracted this article because the content of this article is nonsensical. The peer review process was not carried out in accordance with the Publisher's peer review policy. The author has not responded to correspondence regarding this retraction.

The original article can be found online at https://doi.org/10.1007/ s12517-021-07247-4.

Ziyan Li

liziyan1088@163.com

1 Institute of Physical Education, Changsha University

of Science and Technology, Changsha 410076, Hunan,

China 